\title{
Optimal Placement of FACTS Controllers for Congestion Management in the Deregulated Power System
}

\author{
S. Surender Reddy \\ Department of Railroad and Electrical Engineering, Woosong University, Republic of Korea
}

\begin{tabular}{l}
\hline \hline Article Info \\
\hline Article history: \\
Received Jan 2, 2018 \\
Revised Mar 5, 2018 \\
Accepted Mar 30, 2018
\end{tabular}

Keyword:

Congestion management

FACTS controllers

Optimal location

Optimal power flow

Performance index

Sensitivity analysis

\begin{abstract}
This paper proposes a methodology to determine the optimal location of Flexible AC Transmission System (FACTS) controllers for Congestion Management $(\mathrm{CM})$ in the restructured electrical power system. An approach to find the optimum placement of Thyristor Controlled Phase Angle Regulators (TCPAR) and Thyristor Controlled Series Compensators (TCSC) has been proposed in this paper. The proposed methodology is based on the sensitivity of transmission loss which a controller is installed. The total system losses and the power flows are considered as the performance indices. The traditional optimal power flow (OPF) problem is modified to include the market players, who will compete and trade simultaneously, ensuring the system operation stays within the security limits. In this paper, pool and bilateral contracts are considered. Here, an integrated methodology is proposed that includes the FACTS Controllers in a bilateral contract framework to maintain the system security and to minimize the deviations from the contractual requirements. The simulation results on IEEE 30 bus system show that the sensitivity factors could be used effectively for the optimal location of FACTS controllers in response to the required objectives.
\end{abstract}

Copyright () 2018 Institute of Advanced Engineering and Science. All rights reserved.

\section{Corresponding Author:}

S. Surender Reddy,

Departement of Railroad and Electrical Engineering,

Woosong University,

Jayan-dong, Dong-gu, Daejeon, Republic of Korea 300718.

Email: salkuti.surenderreddy@gmail.com

\section{INTRODUCTION}

The deregulation of electrical power industry has involved paradigm shifts in the real-time control actions of power grids. Optimal power flow (OPF) is the most useful tool for obtaining the optimum generation cost in the system considering the existing operational and transmission constraints. With the trend of an increasing number of bilateral dispatch contracts, the possibility of insufficient resources leads to the network congestion. The operational aspects of power systems pose some of the most challenging problems encountered in the deregulation of electrical power industry. In this scenario, Congestion Management (CM) within an OPF framework becomes the most important issue. Congestion can be revealed by incorporating the transmission line capacity limits in the scheduling and dispatch process. This may involve the re-dispatch of generation and/or load curtailment. The other possible ways of relieving the congestion are the Flexible AC Transmission System (FACTS) devices or operation of phase-shifters. Variable Series Capacitors, Unified Power Flow Controllers (UPFC) and Phase Shifters can be utilized to change the transmission line flow by changing their parameters to achieve different objectives [1]. In the electricity markets, the Independent System Operator (ISO) is responsible to determine the necessary actions such that no violations of grid constraints occur. The comprehensive set of actions referred as CM, which principally consists of rescheduling of generation and loads, so as to establish a system state without violations of system constraints. The cost of CM plays a vital role in attaining the secure state. 
CM actions are based on the issuing orders by the ISO to different participants to re-dispatch generators, reschedule their contracts, use various controllers or load sheds in the extreme conditions, when these measures are not able to mitigate the congestion [2]. The other possible solutions are based on determining the new contracts that redirect flows on the congested lines. Phase shifters, tap changing transformers and FACTS devices may play a major lines in the restructured electricity markets to manage the congestion [3], [4]. FACTS controllers [5] provide control facilities in the steady state power flow control and the dynamic stability control. CM problem by with optimally placing the FACTS devices has been proposed in the References [6]. An efficient and simple model for the optimal placement of UPFC for the $\mathrm{CM}$ is proposed in [7]. Reference [8] presents a generalized approach for the determination of optimal locations for the placement of FACTs devices in the power system with an objective of reducing real power loss and to reduce the overloading of lines. In [9], an approach which is the combination of bacterial foraging technique with Nelder-Mead approach is utilized to solve the OPF problems, and then the optimal placement of the TCSC controllers are determined for solving the CM problem. Reference [10] proposes a new CM approach considering the load variation pattern and the ZIP load model in the day-ahead (DA) electricity market. Reference [11] presents the CM approach in a centralized electricity market with the consideration of voltage stability as the loadability limit. In [12], an Improved Particle Swarm Optimization (IPSO) algorithm is presented to determine the optimal settings for the present infrastructure as well as the optimal placement, sizes and control settings for the Static Compensator units. In [13], a demand-side based CM approach to manage the congestion has been proposed for the centralized electricity market. In [14], an optimization problem is formulated to alleviate the congestion and provide better operating conditions for the market participants. Reference [15] presents the optimal location of FACTS controllers considering the branch loading, voltage stability and loss minimization objectives using the Genetic Algorithm (GA). In [16], harmony search technique is used for the proper tuning of Interline Power Flow Converter for a multiobjective function which reduces the power losses, voltage deviations and the security margin. The goal of reference [17] is to serve as a guide for selecting the right power system analysis and optimization technique for a given transmission system problem. In [18], total real and reactive power loss deviation based sensitivity indexes with rank co-relation concept, has been proposed for the optimal location and operating range of TCSC. The generators' rescheduling based CM approach to manage congestion considering loadability limit has been presented in [19]. The viability and technical merits of boosting ATC using TCSC are analyzed in [20].

All the papers in the literature, do not suggest a reliable and simple approach for determining the optimal placement of FACTS controllers in the restructured power systems. If there is no congestion in the system then the location of FACTS controllers from the static point of view can be decided by reducing the total system losses. But, this methodology is inadequate when the congestion occurs in the system. An approach based on the real power Performance Index (PI) has been considered in this paper due to the stability and security reasons. In this paper, an OPF based solution is developed for solving the CM problem by incorporating the FACTS controllers in the bilateral or centralized market model. The FACTS controllers are operated in such a way that the contractual agreements must be fulfilled by minimizing the transmission line congestion. The objective functions considered are the minimization of cost and the minimization of transaction deviations. In the pool based market operation, the sellers (i.e., generators) submit their decremental and incremental bidding prices in the real-time (RT) market. These things can be included in the OPF problem to yield the decremental/incremental change in generator outputs. In the same way, in the bilateral based market operation, every transaction contract may involve a compensation price that the sellerbuyer pair is ready to accept and its transaction to be curtailed. In this paper, an approach to find the optimal placement of Thyristor Controlled Phase Angle Regulators (TCPAR) and Thyristor Controlled Series Compensators (TCSC) has been proposed. The proposed methodology is based on the sensitivity of 3 factors, and they are transmission loss on a line in which a controller to be installed, real power loss of complete system and the performance index of real power flow. The effectiveness of the proposed algorithm has been demonstrated on standard IEEE 30 bus test system.

The remainder of the paper is organized as follows. Section 2 presents the modeling of FACTS controllers (i.e., TCSC and TCPAR). The objective functions and their constraints are presented in Section 3. Section 4 describes the proposed CM approaches for the optimal placement of FACTS controllers. Simulation results and discussion are presented in Section 4. Finally, Section 5 brings out the contributions with concluding remarks.

\section{STATIC MODELING OF FACTS CONTROLLERS}

\subsection{Modeling of thyristor controlled series capacitor (TCSC)}

Modeling of a transmission line with a TCSC connected between the buses $\mathrm{i}$ and $\mathrm{j}$ is represented in Figure 1. 


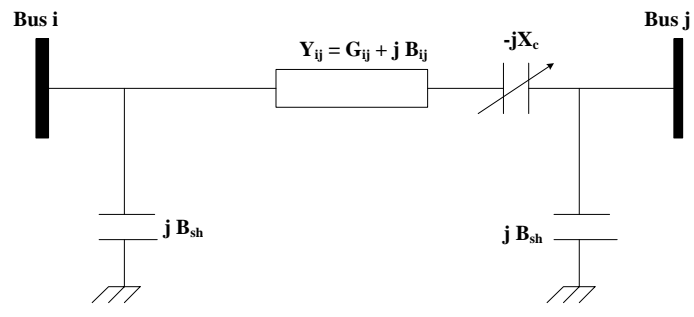

Figure 1. Model of TCSC connected between buses $\mathrm{i}$ and $\mathrm{j}$

During the steady state operation, the TCSC can be considered as a static reactance of $-\mathrm{j} \mathrm{X}_{\mathrm{c}}$. The active and reactive power flows from bus i to bus $\mathrm{j}\left(P_{i j}^{c}\right.$ and $\left.Q_{i j}^{c}\right)$ of a line having the series impedance $Z_{i j}$, and a series reactance (i.e., $-\mathrm{j} X_{c}$ ) are represented as,

$$
\begin{aligned}
& P_{i j}^{c}=V_{j}^{2} G_{i j}^{\prime}-V_{i} V_{j}\left[G_{i j}^{\prime} \cos \delta_{i j}+B_{i j}^{\prime} \sin \delta_{i j}\right] \\
& Q_{i j}^{c}=-V_{i}^{2}\left(B_{i j}^{\prime}+B_{s h}\right)-V_{i} V_{j}\left[G_{i j}^{\prime} \cos \delta_{i j}-B_{i j}^{\prime} \sin \delta_{i j}\right]
\end{aligned}
$$

The real power loss $\left(P_{L K}^{c}\right)$ in line $\mathrm{k}$ connected between buses $\mathrm{i}$ and $\mathrm{j}$ is expressed as,

$$
P_{L K}^{c}=V_{i}^{2} G_{i j}^{\prime}+V_{j}^{2} G_{i j}^{\prime}-2 V_{i} V_{j} G_{i j}^{\prime} \cos \delta_{i j}
$$

where $G_{i j}^{\prime}=\frac{r_{i j}}{r_{i j}^{2}+\left(x_{i j}-x_{c}\right)^{2}}$ and $B_{i j}^{\prime}=\frac{-\left(x_{i j}-x_{c}\right)}{r_{i j}^{2}+\left(x_{i j}-x_{c}\right)^{2}}$.

The change in transmission line flow due to the series capacitance can be expressed as a line without series capacitance with power injected at the receiving and sending ends of transmission line as depicted in Figure 2. The active power injections at bus i (i.e., $\mathrm{P}_{\mathrm{ic}}$ ) and bus $\mathrm{j}$ (i.e., $\mathrm{P}_{\mathrm{jc}}$ ) can be represented using,

$$
\begin{aligned}
& P_{i c}=V_{i}^{2} \Delta G_{i j}-V_{i} V_{j}\left[\Delta G_{i j} \cos \delta_{i j}+\Delta B_{i j} \sin \delta_{i j}\right] \\
& P_{j c}=V_{j}^{2} \Delta G_{i j}-V_{i} V_{j}\left[\Delta G_{i j} \cos \delta_{i j}-\Delta B_{i j} \sin \delta_{i j}\right]
\end{aligned}
$$

In the same way, the reactive power injections at bus $\mathrm{i}$ (i.e., $\mathrm{Q}_{\mathrm{ic}}$ ) and bus $\mathrm{j}$ (i.e., $\mathrm{Q}_{\mathrm{jc}}$ ) can be represented using,

$$
\begin{aligned}
& Q_{i c}=-V_{i}^{2} \Delta B_{i j}-V_{i} V_{j}\left[\Delta G_{i j} \sin \delta_{i j}-\Delta B_{i j} \cos \delta_{i j}\right] \\
& Q_{j c}=V_{j}^{2} \Delta B_{i j}+V_{i} V_{j}\left[\Delta G_{i j} \sin \delta_{i j}+\Delta B_{i j} \cos \delta_{i j}\right]
\end{aligned}
$$

where $\Delta G_{i j}=\frac{x_{c} r_{i j}\left(x_{c}-2 x_{i j}\right)}{\left(r_{i j}^{2}+x_{i j}^{2}\right)\left[r_{i j}^{2}+\left(x_{i j}-x_{c}\right)^{2}\right]}$ and $\Delta B_{i j}=\frac{-x_{c}\left(r_{i j}^{2}-x_{i j}^{2}+x_{c} x_{i j}\right)}{\left(r_{i j}^{2}+x_{i j}^{2}\right)\left[r_{i j}^{2}+\left(x_{i j}-x_{c}\right)^{2}\right]}$.

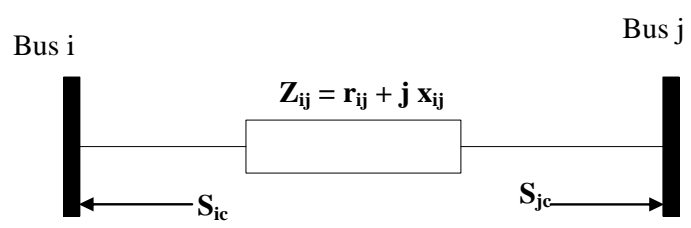

Figure 2. The injection model of TCSC connected between buses $\mathrm{i}$ and $\mathrm{j}$ 


\subsection{Modeling of thyristor controlled phase angle regulator (TCPAR)}

The active and reactive power flow expressions with TCPAR are expressed as,

$$
\begin{aligned}
& P_{i j}^{S}=V_{i}^{2} T^{2} G_{i j}-V_{i} V_{j}\left[G_{i j} \cos \left(\delta_{i j}+\varphi\right)+B_{i j} \sin \left(\delta_{i j}+\varphi\right)\right] \\
& Q_{i j}^{S}=-V_{i}^{2} T^{2} B_{i j}-V_{i} V_{j} T\left[G_{i j} \sin \left(\delta_{i j}+\varphi\right)-B_{i j} \cos \left(\delta_{i j}+\varphi\right)\right]
\end{aligned}
$$

In the above equation, $\mathrm{T}=\sec \varphi$. The real power loss $\left(\mathrm{P}_{\mathrm{Lk}}\right)$ in the line having TCPAR can be represented using,

$$
P_{L K}^{S}=V_{i}^{2} T^{2} G_{i j}+V_{j}^{2} G_{i j}-2 V_{i} V_{j} T G_{i j} \cos \left(\delta_{i j}+\varphi\right)
$$

The injection model of TCPAR is depicted in Figure 3. The active power injected at bus i (i.e., $\mathrm{P}_{\mathrm{is}}$ ), bus $j$ (i.e., $\left.P_{j s}\right)$, and the reactive powers $\left(Q_{i s}\right.$ and $\left.Q_{j s}\right)$ of a line having a phase shifter are expressed as,

$$
\begin{aligned}
& P_{i s}=-V_{i}^{2} K^{2} G_{i j}-V_{i} V_{j} K\left(G_{i j} \sin \delta_{i j}-B_{i j} \cos \delta_{i j}\right) \\
& P_{j s}=-V_{i} V_{j} K\left(G_{i j} \sin \delta_{i j}+B_{i j} \cos \delta_{i j}\right) \\
& Q_{i s}=-V_{i}^{2} K^{2} B_{i j}+V_{i} V_{j} K\left(G_{i j} \cos \delta_{i j}+B_{i j} \sin \delta_{i j}\right) \\
& Q_{j s}=-V_{i} V_{j} K\left(G_{i j} \cos \delta_{i j}-B_{i j} \sin \delta_{i j}\right)
\end{aligned}
$$

In the above equations, $\mathrm{K}=\tan \varphi$.

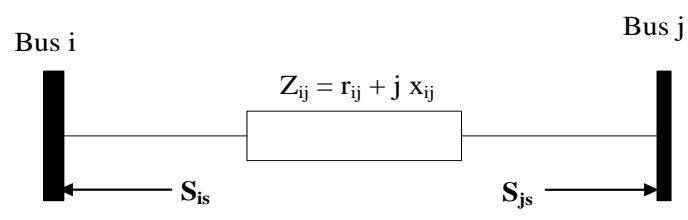

Figure 3. The injection model of TCPAR connected between buses $i$ and $j$

\section{CONGESTION MANAGEMENT (CM): PROBLEM FORMULATION}

The objective of $\mathrm{CM}$ problem is to alleviate the congestion and to improve the voltage profile. For this purpose, the FACTS devices, i.e., TCSC and TCPAR are incorporated in the proposed problem [21], [22]. These two objectives are formulated next:

\subsection{Objective 1: Minimization overload/ congestion alleviation}

This objective function is formulated as [15],

$$
\text { Minimize, } \quad J_{1}=\sum_{i=1}^{N O L}\left(S_{i}-S_{i}^{\max }\right)
$$

\subsection{Objective 2: Transmission loss minimization}

For the reactive power optimization or to improve the voltage profile in the power system, the transmission losses minimization is considered as the objective function.

Minimize, total system transmission losses, i.e.,

$$
\text { Minimize, } \quad J_{2}=\frac{1}{2} \sum_{i=1}^{n} \sum_{j=1, j \neq i}^{n} G_{i j}\left[V_{i}^{2}+V_{j}^{2}-2 V_{i} V_{j} \cos \left(\delta_{i}-\delta_{j}\right)\right]
$$

In this paper, these two objectives are optimized simultaneously using the weighted summation approach. The augmented objective function using this approach is formulated as, Minimize,

$$
J=W_{1}\left(J_{1}\right)+W_{2}\left(J_{2}\right)
$$


The above objective function is solved subjected to the following constraints.

\subsection{Equality constraints}

$$
\begin{array}{ll}
P_{G i}-P_{D i}-V_{i} \sum_{j=1}^{n} V_{j}\left(G_{i j} \cos \delta_{i j}+B_{i j} \sin \delta_{i j}\right) & i=1,2, \ldots, n \\
Q_{G i}-Q_{D i}-V_{i} \sum_{j=1}^{n} V_{j}\left(G_{i j} \sin \delta_{i j}-B_{i j} \cos \delta_{i j}\right) & i=1,2, \ldots, n
\end{array}
$$

\subsection{Inequality constraints}

a. Generator Constraints: Generator active power $\left(\mathrm{P}_{\mathrm{Gi}}\right)$, reactive power $\left(\mathrm{Q}_{\mathrm{Gi}}\right)$ and voltage magnitudes $\left(\mathrm{V}_{\mathrm{Gi}}\right)$ are limited by their minimum and maximum limits [24].

$$
\begin{array}{cc}
P_{G i}^{\min } \leq P_{G i} \leq P_{G i}^{\max } & i=1,2,3, \ldots, N_{G} \\
Q_{G i}^{\min } \leq Q_{G i} \leq Q_{G i}^{\max } & i=1,2,3, \ldots, N_{G} \\
V_{G i}^{\min } \leq V_{G i} \leq V_{G i}^{\max } & i=1,2,3, \ldots, N_{G}
\end{array}
$$

b. Transformer Constraints: Transformer taps have lower and upper setting limits are expressed as,

$$
T_{i}^{\min } \leq T_{i} \leq T_{i}^{\max } \quad i=1,2,3, \ldots, N_{T}
$$

c. Switchable VAR sources: The switchable VAR sources are restricted by,

$$
Q_{C i}^{\min } \leq Q_{C i} \leq Q_{C i}^{\max } \quad i=1,2,3, \ldots, N_{C}
$$

d. Security constraints: These constraints include the limits on load bus voltage magnitudes and line flow limits. They are expressed as,

$$
\begin{array}{ll}
V_{D i}^{\min } \leq V_{D i} \leq V_{D i}^{\max } & i=1,2,3, \ldots, N_{D} \\
S_{L i} \leq S_{L i}^{\max } & i=1,2,3, \ldots, N_{\text {line }}
\end{array}
$$

\subsection{Opposition based bacterial dynamics algorithm (OBDA)}

In OBDA, one primary bacterium and two secondary bacteria, i.e., associated and opposite associated bacterium are used. The primary bacterium is initialized randomly within the decision space. Then, an associated bacterium is generated by moving the primary bacterium in one dimension between upper and lower bounds. After that an opposite associated bacterium is generated by moving the primary bacterium in the same dimension, but in the opposite direction to that of associated bacterium [24]. For the detailed description of OBDA, the reader may refer [25].

\section{PROPOSED APPROACHES FOR OPTIMAL PLACEMENT OF FACTS DEVICES}

For the optimal location of FACTS controllers, this paper utilizes a static considerations based on three factors, i.e., reduction in active power loss of a line $\mathrm{k}$ (i.e., $\mathrm{P}_{\mathrm{Lk}}$ ), reduction in the total system active power loss (i.e., $\mathrm{P}_{\mathrm{LT}}$ ) and the reduction in active power flow performance index (PI). Using a FACTS controller, one can reduce the power loss in a line using the optimal location of the device. However, an increase in the total system loss and/or may increase the overloading elsewhere in the system. The reduction in the active power loss will eliminate or reduce the unwanted loop flows. However, there is no guarantee that the transmission lines will not be overloaded though this is unlikely in the absence of congestion.

\subsection{Approach 1: Line loss sensitivity indices}

Define the sensitivity $\mathrm{a}_{\mathrm{k}}{ }^{\mathrm{c}}$ of transmission loss $\left(\mathrm{P}_{\mathrm{Lk}}\right)$ on a series compensated transmission line ' $\mathrm{k}$ ' with respective series capacitive reactance $\left(\mathrm{x}_{\mathrm{ck}}\right)$, and the sensitivity $\mathrm{a}_{\mathrm{k}}{ }^{\mathrm{s}}$ with respect to (w.r.t.) phase angle shift $\varphi_{\mathrm{k}}$, on a phase regulated line is represented as,

$$
\mathrm{a}_{\mathrm{k}}^{\mathrm{c}}=\left.\frac{\partial \mathrm{P}_{\mathrm{LK}}^{\mathrm{c}}}{\partial \mathrm{x}_{\mathrm{ck}}}\right|_{\mathrm{x}_{\mathrm{ck}=0}}=\text { line loss sensitivity w. r. t TCSC in line } \mathrm{k}\left(\mathrm{k}=1, \ldots, \mathrm{N}_{\mathrm{l}}\right)
$$




$$
\mathrm{a}_{\mathrm{k}}^{\mathrm{s}}=\left.\frac{\partial \mathrm{P}_{\mathrm{LK}}^{\mathrm{s}}}{\partial \varphi_{\mathrm{k}}}\right|_{\varphi_{\mathrm{k}=0}}=\text { line loss sensitivity w.r.t TCPAR in line } \mathrm{k}\left(\mathrm{k}=1, \ldots, \mathrm{N}_{\mathrm{l}}\right.
$$

Therefore, from the Equations (3) and (10), at base power flow, we get,

$$
\begin{aligned}
& \mathrm{a}_{\mathrm{k}}^{\mathrm{c}}=\left.\frac{\partial \mathrm{P}_{\mathrm{LK}}^{\mathrm{c}}}{\partial \mathrm{x}_{\mathrm{ck}}}\right|_{\mathrm{x}_{\mathrm{ck}=0}}=-2\left(V_{i}^{2}+V_{j}^{2}-2 V_{i} V_{j} G_{i j} \cos \delta_{i j}\right) G_{i j} B_{i j} \\
& \mathrm{a}_{\mathrm{k}}^{\mathrm{s}}=\left.\frac{\partial \mathrm{P}_{\mathrm{LK}}^{\mathrm{s}}}{\partial \varphi_{\mathrm{k}}}\right|_{\varphi_{\mathrm{k}=0}}=\left(2 V_{i} V_{j} \sin \delta_{i j}\right) G_{i j}
\end{aligned}
$$

\subsection{Approach 2: Total system loss sensitivity indices}

The exact transmission loss formula of a system is expressed as,

$$
P_{L T}^{\prime}=\sum_{j=1}^{N} \sum_{k=1}^{N}\left[\alpha_{j k}\left(P_{j} P_{k}+Q_{j} Q_{k}\right)+\beta_{j k}\left(O_{j} P_{k}-P_{j} Q_{k}\right)\right]
$$

where $\mathrm{N}$ is the total number of buses in the system, $\mathrm{P}_{\mathrm{j}}$ and $\mathrm{Q}_{\mathrm{j}}$ are the active and reactive power injections at bus j. $\alpha, \beta$ are the loss coefficients, and they are represented as,

$$
\begin{aligned}
& \alpha_{j k}=\frac{r_{j k}}{V_{j} V_{k}} \cos \left(\delta_{j}-\delta_{k}\right) \\
& \beta_{j k}=\frac{r_{j k}}{V_{j} V_{k}} \sin \left(\delta_{j}-\delta_{k}\right)
\end{aligned}
$$

where $r_{j k}$ is the real part of $j-k^{\text {th }}$ element of $\left[Z_{\text {bus }}\right]$ matrix. This total loss, if FACTS controller, one at a time is used, can be expressed as,

$$
\mathrm{P}_{\mathrm{LT}}=\left\{\begin{array}{lc}
P_{L T}^{\prime}-\left(P_{i c}-P_{j c}\right) & \text { for } T C S C \\
P_{L T}^{\prime}-\left(P_{i s}-P_{j s}\right) & \text { for TCPAR }
\end{array}\right.
$$

The total system active power loss sensitivity factors w.r.t. the parameters of TCSC and TCPAR can be expressed as,

$$
\begin{aligned}
& \mathrm{b}_{\mathrm{k}}^{\mathrm{c}}=\left.\frac{\partial \mathrm{P}_{\mathrm{LT}}}{\partial \mathrm{x}_{\mathrm{ck}}}\right|_{\mathrm{x}_{\mathrm{ck}=0}}=\text { Total line loss sensitivity w.r.t TCSC in line } \mathrm{k}\left(\mathrm{k}=1, \ldots \mathrm{N}_{\mathrm{l}}\right) \\
& \mathrm{b}_{\mathrm{k}}^{\mathrm{s}}=\left.\frac{\partial \mathrm{P}_{\mathrm{LT}}}{\partial \varphi_{\mathrm{k}}}\right|_{\varphi_{\mathrm{k}=0}}=\text { Total line loss sensitivity w.r.t TCPAR in line } \mathrm{k}\left(\mathrm{k}=1, \ldots \mathrm{N}_{\mathrm{l}}\right)
\end{aligned}
$$

These factors are computed using the Equations (30) and (31) at a base load flow solution. Let, a line ' $\mathrm{k}$ ' is connected between bus $i$ and bus $j$. The total system loss sensitivity w.r.t. TCSC and TCPAR can be expressed as,

$$
\begin{aligned}
& \mathrm{b}_{\mathrm{k}}^{\mathrm{c}}=\left.\frac{\partial \mathrm{P}_{\mathrm{LT}}}{\partial \mathrm{P}_{\mathrm{i}}} \frac{\partial \mathrm{P}_{\mathrm{i}}}{\partial \mathrm{x}_{\mathrm{ck}}}\right|_{\mathrm{x}_{\mathrm{ck}=0}}+\left.\frac{\partial \mathrm{P}_{\mathrm{LT}}}{\partial \mathrm{P}_{\mathrm{j}}} \frac{\partial \mathrm{P}_{\mathrm{j}}}{\partial \mathrm{x}_{\mathrm{ck}}}\right|_{\mathrm{x}_{\mathrm{ck}=0}}+\left.\frac{\partial \mathrm{P}_{\mathrm{LT}}}{\partial \mathrm{Q}_{\mathrm{i}}} \frac{\partial \mathrm{Q}_{\mathrm{i}}}{\partial \mathrm{x}_{\mathrm{ck}}}\right|_{\mathrm{x}_{\mathrm{ck}=0}}+\left.\frac{\partial \mathrm{P}_{\mathrm{LT}}}{\partial \mathrm{Q}_{\mathrm{j}}} \frac{\partial \mathrm{Q}_{\mathrm{j}}}{\partial \mathrm{x}_{\mathrm{ck}}}\right|_{\mathrm{x}_{\mathrm{ck}=0}}-\left.\left(\frac{\partial \mathrm{P}_{\mathrm{ic}}}{\partial \mathrm{x}_{\mathrm{ck}}}+\frac{\partial \mathrm{P}_{\mathrm{jc}}}{\partial \mathrm{x}_{\mathrm{ck}}}\right)\right|_{\mathrm{x}_{\mathrm{ck}=0}} \\
& b_{\mathrm{k}}^{\mathrm{S}}=\left.\frac{\partial \mathrm{P}_{\mathrm{LT}}}{\partial \mathrm{P}_{\mathrm{i}}} \frac{\partial \mathrm{P}_{\mathrm{i}}}{\partial \varphi_{\mathrm{k}}}\right|_{\varphi_{\mathrm{k}=0}}+\left.\frac{\partial \mathrm{P}_{\mathrm{LT}}}{\partial \mathrm{P}_{\mathrm{j}}} \frac{\partial \mathrm{P}_{\mathrm{j}}}{\partial \varphi_{\mathrm{k}}}\right|_{\varphi_{\mathrm{k}=0}}+\left.\frac{\partial \mathrm{P}_{\mathrm{LT}}}{\partial \mathrm{Q}_{\mathrm{i}}} \frac{\partial \mathrm{Q}_{\mathrm{i}}}{\partial \varphi_{\mathrm{k}}}\right|_{\varphi_{\mathrm{k}}=0}+\left.\frac{\partial \mathrm{P}_{\mathrm{LT}}}{\partial \mathrm{Q}_{\mathrm{j}}} \frac{\partial \mathrm{Q}_{\mathrm{j}}}{\partial \varphi_{\mathrm{k}}}\right|_{\varphi_{\mathrm{k}}=0}-\left(\frac{\partial \mathrm{P}_{\mathrm{is}}}{\partial \varphi_{\mathrm{k}}}+\left.\frac{\partial \mathrm{P}_{\mathrm{is}}}{\partial \varphi_{\mathrm{k}}}\right|_{\varphi_{\mathrm{k}=0}}\right.
\end{aligned}
$$

where $\frac{\partial P_{L T}}{\partial P_{i}}=2 \sum_{m=1}^{N}\left(\alpha_{i m} P_{m}-\beta_{i m} Q_{m}\right), \frac{\partial P_{L T}}{\partial Q_{i}}=2 \sum_{m=1}^{N}\left(\alpha_{i m} Q_{m}-\beta_{i m} P_{m}\right)$.

\subsection{Criteria for the optimal placement of FACTS controllers}

The FACTS controller must be placed on the most sensitive lines. Using the sensitivity indices calculated for each type of FACTS controller, the following criterion is used for selecting the optimal placement:

a. TCSC must be placed in a transmission line ' $k$ ' having the most negative sensitivity index.

b. TCPAR must be placed in a transmission line ' $k$ ' having the largest absolute value of sensitivity factor. 
c. The additional criteria can also be used while deciding the optimal location of FACTS controllers that the TCSC and TCPAR must not be placed with generating transformer, even though the sensitivity index is highest.

\section{RESULTS AND DISCUSSION}

In this paper, IEEE 30 bus system [26] is selected to test the effectiveness of the proposed approach. The simulation results obtained on this system presents that the sensitivity factors can be used effectively for the optimal location in response to the required objectives. Suppose, if there is no congestion in the system, then the location of TCSC from the static point of view can be determined based on the maximum negative sensitivity $\left(b_{k}{ }^{c}\right)$. But, the maximum absolute value of sensitivity $\left(b_{k}{ }^{s}\right)$ is the choice for the TCPAR. The transmission network congestion within the network can be alleviated by choosing the optimal location and setting of FACTS controllers. In this paper, two approaches are proposed. For the first approach, FACTS controller location is selected randomly, and for second approach, the optimal location is determined to install a FACTS controller.

\subsection{Optimal setting of FACTS controllers for CM}

Table 1 presents the arbitrary locations and settings of TCSC and TCPAR in the lines for solving the CM problem. Without considering the FACTS controllers, the total cost arising out of congestion is 1011.2\$. But, by considering the same bilateral and multilateral transaction, the congestion is removed by choosing proper settings of FACTS controllers. Then, the total cost obtained is $925.156 \$$, which is much lesser than the former. In this paper, we considered that TCSC setting (i.e., reactance of TCSC $\left(\mathrm{X}_{\mathrm{c}}\right)$ ) of a particular line should not be exceed $50 \%$ of its reactance due to some limitation and resonance problem. Similarly, the TCPAR setting should not be exceeding $\pm 5^{0}$.

Table 1. Optimal Locations and Settings of TCSC and TCPAR for Congestion Management (CM)

\begin{tabular}{cccc}
\hline Line No. & TCSC Setting (Reactance in p.u.) & Line No. & TCPAR Setting (in degrees) \\
\hline $1-2$ & 0 & $6-10$ & 0.6801 \\
$3-4$ & 0.019 & $4-12$ & 4.79 \\
$2-5$ & 0 & $10-22$ & 2.7596 \\
& & $28-27$ & 0.4382 \\
\hline
\end{tabular}

\subsection{Optimal placement of TCSC for CM}

From Table 2, it can be observed that, only lines 29, 4, 7 and 10 are suitable for the placement of TCSC as the sensitivities of Performance Index (PI) w.r.t. the TCSC control parameter are more negative for these transmission lines. The simulation results of optimal scheduling with TCSC placement in each line, one at a time, are depicted in Table 2. The maximum value of series compensation in each transmission line is limited to $50 \%$ of each line to avoid the sub-synchronous resonance problem. The placement of TCSC in line 29 removes the congestion without curtailment of any pool or bilateral contract. This presents that the sensitivity approach is suitable for the optimal location of TCSC Controllers in the system for solving the CM problem.

Table 2. Sensitivity Indices at Different Buses for TCSC and TCPAR

\begin{tabular}{|c|c|c|c|c|c|}
\hline Line & Line $\mathrm{k}$ & \multicolumn{2}{|c|}{ Sensitivity Indices for TCSC } & \multicolumn{2}{|c|}{ Sensitivity Indices for TCPAR } \\
\hline Number & $(\mathrm{i} \rightarrow \mathrm{j})$ & Approach $1\left(a_{k}^{c}\right)$ & Approach $2\left(b_{k}^{c}\right)$ & Approach $1\left(a_{k}^{S}\right)$ & Approach $2\left(b_{k}^{S}\right)$ \\
\hline 1 & $1 \rightarrow 2$ & -2.8995 & -1.8003 & 9.8952 & 2.547 \\
\hline 2 & $1 \rightarrow 3$ & -0.9443 & -0.1816 & 2.3556 & 0.5964 \\
\hline 3 & $2 \rightarrow 4$ & -0.9631 & -0.1979 & 3.2302 & 0.803 \\
\hline 4 & $3 \rightarrow 4$ & -4.3604 & -4.1088 & 15.5218 & 3.7957 \\
\hline 5 & $2 \rightarrow 5$ & -0.8844 & -0.1588 & 2.1515 & 0.5327 \\
\hline 6 & $2 \rightarrow 6$ & -0.9481 & -0.1920 & 3.1935 & 0.7932 \\
\hline 7 & $4 \rightarrow 6$ & -4.1344 & -3.5615 & 12.1461 & 2.9471 \\
\hline 8 & $5 \rightarrow 7$ & -1.3804 & -0.4254 & 5.5948 & 1.3399 \\
\hline 9 & $6 \rightarrow 7$ & -2.0432 & -0.8894 & 6.7997 & 1.6336 \\
\hline 10 & $6 \rightarrow 8$ & -4.0791 & -3.4635 & 11.9116 & 2.8787 \\
\hline 11 & $6 \rightarrow 9$ & -0.8909 & -0.1515 & 0 & 0 \\
\hline 12 & $6 \rightarrow 10$ & -0.3333 & -0.0212 & 0 & 0 \\
\hline 13 & $9 \rightarrow 11$ & -0.8909 & -0.1515 & 0 & 0 \\
\hline 14 & $9 \rightarrow 10$ & -1.6846 & -0.5416 & 0 & 0 \\
\hline 15 & $4 \rightarrow 12$ & -0.7239 & -0.100 & 0 & 0 \\
\hline
\end{tabular}




\begin{tabular}{|c|c|c|c|c|c|}
\hline \multirow{2}{*}{$\begin{array}{c}\text { Line } \\
\text { Number }\end{array}$} & \multirow{2}{*}{$\begin{array}{c}\text { Line k } \\
(\mathrm{i} \rightarrow \mathrm{j})\end{array}$} & \multicolumn{2}{|c|}{ Sensitivity Indices for TCSC } & \multicolumn{2}{|c|}{ Sensitivity Indices for TCPAR } \\
\hline & & Approach $1\left(a_{k}^{c}\right)$ & Approach $2\left(b_{k}^{c}\right)$ & Approach $1\left(a_{k}^{S}\right)$ & Approach $2\left(b_{k}^{S}\right)$ \\
\hline 16 & $12 \rightarrow 13$ & -1.3236 & -0.3344 & 0 & 0 \\
\hline 17 & $12 \rightarrow 14$ & -0.5881 & -0.0823 & 2.8912 & 0.7546 \\
\hline 18 & $12 \rightarrow 15$ & -1.1299 & -0.3103 & 5.8625 & 1.5231 \\
\hline 19 & $12 \rightarrow 16$ & -0.7606 & -0.137 & 3.697 & 0.9669 \\
\hline 20 & $14 \rightarrow 15$ & -0.4171 & -0.075 & 4.7177 & 1.2084 \\
\hline 21 & $16 \rightarrow 17$ & -0.8142 & -0.1514 & 3.5656 & 0.9164 \\
\hline 22 & $15 \rightarrow 18$ & -0.6833 & -0.112 & 3.4296 & 0.8662 \\
\hline 23 & $18 \rightarrow 19$ & -1.1524 & -0.3194 & 5.8252 & 1.4535 \\
\hline 24 & $19 \rightarrow 20$ & -2.1801 & -1.1481 & 11.1409 & 2.7833 \\
\hline 25 & $10 \rightarrow 20$ & -0.7385 & -0.1264 & 3.3804 & 0.8602 \\
\hline 26 & $10 \rightarrow 17$ & -1.9119 & -0.8086 & 7.4925 & 1.9249 \\
\hline 27 & $10 \rightarrow 21$ & -2.0348 & -0.9724 & 9.6627 & 2.4655 \\
\hline 28 & $10 \rightarrow 22$ & -1.0008 & -0.239 & 4.9609 & 1.2665 \\
\hline 29 & $21 \rightarrow 22$ & -6.3241 & -9.5954 & 31.7703 & 8.0156 \\
\hline 30 & $15 \rightarrow 23$ & -0.7368 & -0.1306 & 3.728 & 0.9407 \\
\hline 31 & $22 \rightarrow 24$ & -0.7328 & -0.1469 & 4.8117 & 1.2013 \\
\hline 32 & $23 \rightarrow 24$ & -0.5539 & -0.0735 & 2.7678 & 0.6873 \\
\hline 33 & $24 \rightarrow 25$ & -0.4239 & -0.0462 & 2.4809 & 0.6105 \\
\hline 34 & $25 \rightarrow 26$ & -0.3367 & -0.0318 & 2.304 & 0.5553 \\
\hline 35 & $25 \rightarrow 27$ & -0.6968 & -0.1196 & 3.7297 & 0.9206 \\
\hline 36 & $28 \rightarrow 27$ & -0.4679 & -0.0418 & 0 & 0 \\
\hline 37 & $27 \rightarrow 29$ & -0.3486 & -0.0301 & 1.8855 & 0.4593 \\
\hline 38 & $27 \rightarrow 30$ & -0.2398 & -0.0143 & 1.302 & 0.3136 \\
\hline 39 & $29 \rightarrow 30$ & -0.3194 & -0.0252 & 1.7274 & 0.408 \\
\hline 40 & $8 \rightarrow 28$ & -0.8414 & -0.1501 & 2.7348 & 0.6599 \\
\hline 41 & $6 \rightarrow 28$ & -2.8655 & -1.7058 & 8.263 & 2.0001 \\
\hline
\end{tabular}

\subsection{Optimal placement of TCPAR for the congestion management (CM)}

From Table 2, it can also be observed that without the FACTS devices, the pool/centralized demands and the bilateral contracts can be curtailed due to the congestion of the network. The pool demands are curtailed to 0.94 p.u. From the sensitivity analysis (i.e., from Table 2), it can be concluded that only lines 29, 4, 7 and 10 are suitable for the placement of TCPAR. The results for TCPAR are selected depending on the final decision of placement.

\section{CONCLUSIONS}

This paper proposes a new approach for solving the Congestion Management (CM) problem in the restructured power systems within an Optimal Power Flow (OPF) framework. A simple and reliable approach is proposed for determining the optimal placement of FACTS controllers in the restructured power system. The traditional OPF problem is modified to create a mechanism that enables the market participants to simultaneously compete and trade, ensuring that the system operation is within the security limits. In this paper, centralized and bilateral dispatch functions of system operation are presented. This paper then presents on the use of FACTS controllers to remove the congestion. An integrated methodology is proposed which includes the FACTS controllers in a bilateral dispatch framework to maintain the system security and to minimize the deviations from the contractual requirements. Here, a sensitivity based methodology is proposed to find the optimal location of FACTS controllers. Simulation results on IEEE 30 bus test system show that the sensitivity factors can be used effectively for the optimal location in response to the required objectives. If there is no congestion in the system, the placement of TCSC from the static point of view can be decided based on the maximum negative sensitivity $\left(b_{k}{ }^{c}\right)$. On the other hand, the maximum absolute value of sensitivity $\left(b_{k}{ }^{s}\right)$ is the choice for the TCPAR.

\section{REFERENCES}

[1] D. Shirmohammadi, B. Wollenberg, A. Vojdani, "Transmission Dispatch and Congestion Management in the Emerging Energy Market Structures”, IEEE Trans. Power Syst., vol. 13, no. 2, pp. 1466-1474, 1998.

[2] Y. Valle, G.K. Venyagamoorthy, S. Mohaghedhi, J.C. Hernandez, R.G. Harley, "Particle Swarm Optimization: Basic Concepts, Variants and Applications in Power Systems", IEEE Trans. Evolutionary Computation, vol. 12, pp. 171-195, Apr. 2008.

[3] W.D. Rosehart, C.A. Cañizares, and V.H. Quintana, "Multi-objective Optimal Power Flows to Evaluate Voltage Security Costs in Power Networks," IEEE Trans. Power Syst., vol. 18, no. 2, pp. 578-587, May 2003.

[4] S.N. Singh, A.K. David, "A New Approach for Placement of FACTS Devices in Open Power Markets", IEEE Power Eng. Rev., vol. 21, no. 9, pp. 58-60, 2001. 
[5] A. Kumara, S.C. Srivastava, S.N. Singh, "Congestion Management in Competitive Power Market: A Bibliographical Survey,” Electric Power System Research, vol. 76, pp. 153-164, 2005.

[6] G.N. Taranto, L.M.V.G. Pinto, M.V.F. Pereira, "Representation of FACTS Devices in Power System Economic Dispatch", IEEE Trans. Power Syst., vol. 7, no. 2, pp. 572-576, 1992.

[7] S.N. Singh, A.K. David, "Optimal Location of FACTS Devices for Congestion Management", Electric Power System Research, vol. 58, pp. 71-79, 2001.

[8] R. Srinivasa Rao, V. Srinivasa Rao, "A generalized approach for determination of optimal location and performance analysis of FACTs devices", International Journal of Electrical Power \& Energy Systems, vol 73, pp. 711-724, Dec. 2015.

[9] R.A. Hooshmand, M.J. Morshed, M. Parastegari, "Congestion management by determining optimal location of series FACTS devices using hybrid bacterial foraging and Nelder-Mead algorithm", Applied Soft Computing, vol. 28, pp. 57-68, Mar. 2015.

[10] A. Kumar, R.K. Mittapalli, "Congestion management with generic load model in hybrid electricity markets with FACTS devices", International Journal of Electrical Power \& Energy Systems, vol. 57, pp. 49-63, May 2014.

[11] A. Kumar, C. Sekhar, "Congestion management with FACTS devices in deregulated electricity markets ensuring loadability limit", International Journal of Electrical Power \& Energy Systems, vol. 46, pp. 258-273, Mar. 2013.

[12] K. Ravi, M. Rajaram, "Optimal location of FACTS devices using Improved Particle Swarm Optimization", International Journal of Electrical Power \& Energy Systems, vol. 49, pp. 33-338, Jul. 2013.

[13] A. Kumar, C. Sekhar, "DSM based Congestion Management in Pool Electricity Markets with FACTS Devices", Energy Procedia, vol. 14, pp. 94-100, 2012.

[14] S. Rahimzadeh, M.T. Bina, "Looking for optimal number and placement of FACTS devices to manage the transmission congestion", Energy Conversion and Management, vol. 52, no. 1, pp. 437-446, Jan. 2011.

[15] S.S. Reddy, M.S. Kumari, M. Sydulu, "Congestion management in deregulated power system by optimal choice and allocation of FACTS controllers using multi-objective genetic algorithm”, IEEE PES T\&D, New Orleans, LA, USA, 2010, pp. 1-7.

[16] A. Mishra, G.V.N. Kumar, "Harmony Search Algorithm Based Optimal Tuning of Interline Power Flow Controller for Congestion Management”, Computational Intelligence in Data Mining, vol. 2, pp. 173-182, Dec. 2015.

[17] A. Hernandez, M.A. Rodriguez, E. Torres, P. Eguia, "A Review and Comparison of FACTS Optimal Placement for Solving Transmission System Issues", International Conference on Renewable Energies and Power Quality, Bilbao (Spain), Mar. 2013, pp. 1-6.

[18] N.R. Kumari Ch, K.C. Sekhar, "Optimal Placement of TCSC Based on Sensitivity Analysis for Congestion Management”, International Journal of Electrical and Computer Engineering, vol. 6, no. 5, pp. 2041-2047, Oct. 2016.

[19] C. Sekhar, A. Kumar, "Congestion Management in Hybrid Electricity Markets with FACTS Devices with Loadability Limits", International Journal of Electrical and Computer Engineering, vol. 2, no. 1, pp. 75-89, Feb. 2012.

[20] P. Pankajam T, J.S. Rao, J. Amarnath, “ATC Enhancement with FACTS Devices Considering Reactive Power Flows Using PTDF”, International Journal of Electrical and Computer Engineering, vol. 3, no. 6, pp. 741-750, Dec. 2013.

[21] A. Mishra, V.N. Kumar G, "Congestion management of deregulated power systems by optimal setting of Interline Power Flow Controller using Gravitational Search algorithm", Journal of Electrical Systems and Information Technology, vol. 4, no. 1, pp. 198-212, May 2017.

[22] M. Kashyap, S. Kansal, "Hybrid approach for congestion management using optimal placement of distributed generator", International Journal of Ambient Energy, pp. 1-11, Jan. 2017.

[23] S.S. Reddy, "Multi-Objective Based Congestion Management Using Generation Rescheduling and Load Shedding”, IEEE Transactions on Power Systems, vol. 32, no. 2, pp. 852-863, Mar. 2017.

[24] S.S. Reddy, "Congestion Management and Voltage Profile Improvement in a Hybrid Power System with FACTS Controllers", International Journal of Applied Engineering Research, vol. 12, no. 9, pp. 2095-2103, 2017.

[25] S.S. Reddy, J.A. Momoh, "Minimum emissions optimal power flow in wind-thermal power system using Opposition based Bacterial Dynamics algorithm," IEEE Power and Energy Society General Meeting, Boston, MA, 2016, pp. 1-5.

[26] Available. [Online]. Available: http://www.ee.washington.edu/research/pstca. 